\title{
A tandem intramolecular Michael-addition/elimination sequence in dihydropyrimidone to quinoline rearrangements
}

\author{
Nikola Stiasni and C. Oliver Kappe* \\ Institute of Chemistry, Organic and Bioorganic Chemistry, Karl-Franzens-University Graz, \\ Heinrichstrasse 28, A-8010 Graz, Austria \\ E-mail: oliver.kappe@uni-graz.at
}

Dedicated to Professor Albert Padwa on the occasion of his $65^{\text {th }}$ birthday

(received 23 Mar 02; accepted 30 Jul 02; published on the web 07 Aug 02)

\begin{abstract}
The attempted synthesis of the unknown 8,10,12-triazatricyclo[7.3.1.02,7]tridecatriene scaffold 6a by cyclization (intramolecular Michael-addition) of 4-(2-aminophenyl)-2-oxo-1,2,3,4tetrahydro-pyrimidine-5-carboxylates of type $\mathbf{5 a}$ is described. The synthesis of the amino precursor $\mathbf{1 0}$ is achieved by microwave-promoted catalytic transfer hydrogenation of the corresponding nitro analog 9. Subsequent acid-catalyzed intramolecular Michael addition leads to the desired polycyclic scaffold $\mathbf{1 1}$ as a transient intermediate which spontaneously disintegrates in a retro-Michael fashion to the quinoline $\mathbf{1 3 .}$
\end{abstract}

Keywords: Biginelli condensation, catalytic transfer hydrogenation, rearrangement, Michael addition, microwave-assisted reactions

\section{Introduction}

Multicomponent reactions (MCRs) are of increasing importance in organic and medicinal chemistry. ${ }^{1}$ In times where a premium is put on speed, diversity, and efficiency in the drugdiscovery process, MCR strategies offer significant advantages over conventional linear-type syntheses. ${ }^{2}$ The Biginelli three-component protocol (Scheme 1) is particularly attractive, ${ }^{3}$ since the resulting dihydropyrimidone (DHPM) scaffold displays a wide range of biological activities which has led to the development of a number of lead compounds based on that structural core. ${ }^{4}$ In recent years, a variety of different combinatorial protocols based on the classical Biginelli MCR have been advanced. ${ }^{3}$ These include, e.g., solution-phase methods, ${ }^{5,6}$ the use of polymersupported reagents, ${ }^{7}$ fluorous-phase conditions, ${ }^{8}$ and several solid-phase protocols in which 
different resin-bound building blocks and linker combinations have been utilized. ${ }^{9-12}$ Although a large number of functionalized DHPMs, 4, can potentially be prepared by employing the abovementioned procedures, the synthesized heterocyclic scaffold in all these cases remains a structurally relatively simple dihydropyrimidone derivative. ${ }^{13}$

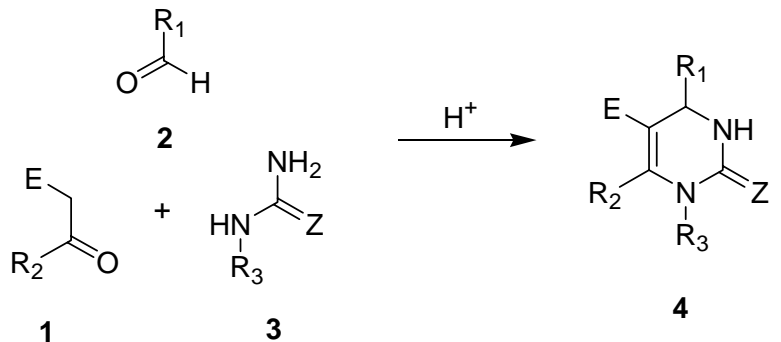

Scheme 1. The Biginelli dihydropyrimidine synthesis $(Z=O, S ; E=$ electron withdrawing group).

For increasing the complexity-generating power ${ }^{14}$ of the classical Biginelli approach, we have considered the preparation of ortho-amino-substituted 4-aryl-DHPMs, i.e., 5a, which in principle could act as precursors to bridged polycyclic derivatives of type 6a (Scheme 2). The generation of this scaffold would permit the introduction of an additional diversity point $\left(\mathrm{R}_{1}\right)$ derived, e.g., from an amine building block introduced via Buchwald-Hartwig type chemistry, ${ }^{15}$ and could be expected to exhibit interesting biological properties in analogy to the known oxygen or sulfur analogs (6b, c) ${ }^{16}$ 8-Oxa-10,12-diazatricyclo[7.3.1.0 $0^{2,7}$ tridecatrienes of type $\mathbf{6 b}$, for example, are readily available in a one-pot Biginelli-type acid-catalyzed cyclo-condensation of urea, acetoacetates, and salicylaldehyde, and can be considered as conformationally rigid calcium channel blockers. ${ }^{16}$ The steric proximity ${ }^{17}$ of the $\mathrm{OH}$ substituent in the ortho position of the aromatic ring, and the C-6 carbon of the pyrimidine ring enables the formation of a sixmembered ring via intramolecular Michael addition. Here we describe our attempts to prepare the corresponding aza-analogs of type 6a starting from the readily available ortho-aminophenylDHPMs $5 \mathbf{a}(\mathrm{X}=\mathrm{NH})$ as precursors.

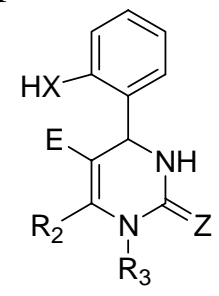

$5 \mathbf{5} ; \mathrm{X}=\mathrm{NR}_{1}$

$5 \mathbf{b} ; X=0$

$5 \mathbf{5} ; \mathrm{X}=\mathrm{S}$

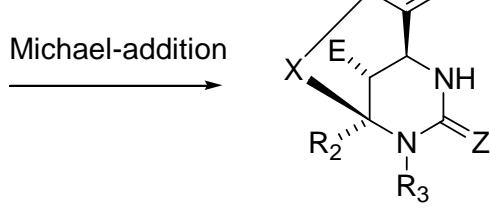

$6 \mathbf{a} ; \mathrm{X}=\mathrm{NR}_{1}$

$6 \mathbf{b} ; X=0$

$6 c ; X=S$

Scheme 2. Polyheterocycles, 6, via intramolecular Michael-addition from Biginelli compounds. 


\section{Results and Discussion}

The easiest entry into 2-aminophenyl-DHPMs appears to be the reduction of the corresponding nitro derivatives. A variety of different nitrophenyl DHPMs have been prepared in recent years by employing the classical Biginelli three-component condensation concept (Scheme 1). ${ }^{18}$ Surprisingly, only in a few cases have subsequent reductions of the nitro group been reported, involving either $\mathrm{Zn} / \mathrm{HCl},{ }^{19} \mathrm{Pt} / \mathrm{H}_{2},{ }^{19}$, or $\mathrm{Pd} / \mathrm{H}_{2}$ conditions. ${ }^{20}$ In continuation of our interest in microwave-assisted synthesis we wanted to evaluate the viability of a sequence of microwavepromoted transformations for the processes described herein.

High-speed microwave-assisted chemistry has attracted a considerable amount of attention in recent years and has been applied successfully in various fields of synthetic organic chemistry, ${ }^{21-29}$ including cycloaddition reactions, ${ }^{22}$ heterocycle synthesis, ${ }^{23}$ the rapid preparation of radio-labeled materials, ${ }^{24}$ transition-metal-catalyzed processes, ${ }^{25}$ solvent-free reactions, ${ }^{26}$ and phase-transfer catalysis. ${ }^{27}$ In fact, it is becoming evident that microwave approaches can be developed for most chemical transformations requiring heat. The main benefits of performing reactions under controlled microwave-irradiation conditions in sealed vessels are the significant rate-enhancements and the higher product yields that can frequently be observed. ${ }^{21-29}$ We were therefore interested in developing a rapid, microwave-assisted protocol for the selective reduction of aromatic nitro groups in DHPMs of the Biginelli type. In previous work, Bose and his coworkers have demonstrated that catalytic-transfer hydrogenations of olefinic substrates, involving ammonium formate and $\mathrm{Pd} / \mathrm{C}$, can be carried out successfully in open vessels under microwave conditions. ${ }^{30}$ More recently, Desai and Danks have developed a variant of this process involving a polymersupported hydrogen donor (on ion-exchange resin) and Wilkinson's catalyst in closed vessels. ${ }^{31}$ None of those microwave-initiated catalytic-transfer hydrogenation strategies seemed to have been adapted for the reduction of nitro groups. For the reduction chemistry required herein we initially employed the corresponding 3-nitrophenyl-DHPM analog 7 as model substrate, which was itself prepared by rapid (10 min) microwave-promoted Biginelli condensation in $79 \%$ yield following our recently disclosed automated protocol (Scheme 3). ${ }^{6}$ Note that under conventional conditions $(\mathrm{EtOH}, \mathrm{HCl})$ this process requires several hours of heating at reflux temperature, and provided the DHPM product 7 in only $57 \%$ isolated yield. ${ }^{19}$ For the desired reduction step we have found that by using 4 equivalents of ammonium formate and a catalytic amount of palladium on charcoal (5\%) a quantitative reduction of the nitro group was achieved within only ca. 2 min of controlled microwave heating at $120{ }^{\circ} \mathrm{C}$ (91\% isolated yield of 8). Owing to the sealed-vessel conditions the pressure inside the microwave reaction vial was raised to $c a .12 \mathrm{bar}$, apparently providing a sufficiently high partial pressure of hydrogen to allow the reaction to proceed in such a short time (Figure 1). It must be noted that we have not observed any reduction of the conjugated enamide double bond of the pyrimidine ring. Even by raising the temperature to $190{ }^{\circ} \mathrm{C}$, employing a large excess of ammonium formate (8 equivalents), and switching to a 
more active catalytic system (palladium hydroxide on charcoal) no reduction of the C5=C6 pyrimidine double bond was observed. ${ }^{32}$<smiles>CCOC(=O)CC(C)=O</smiles>

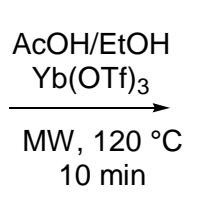

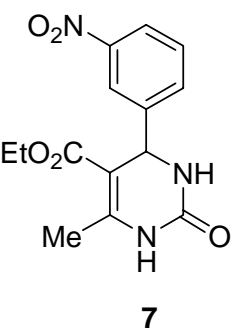
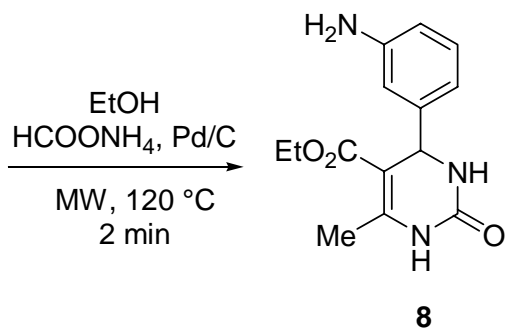

\section{Scheme 3}

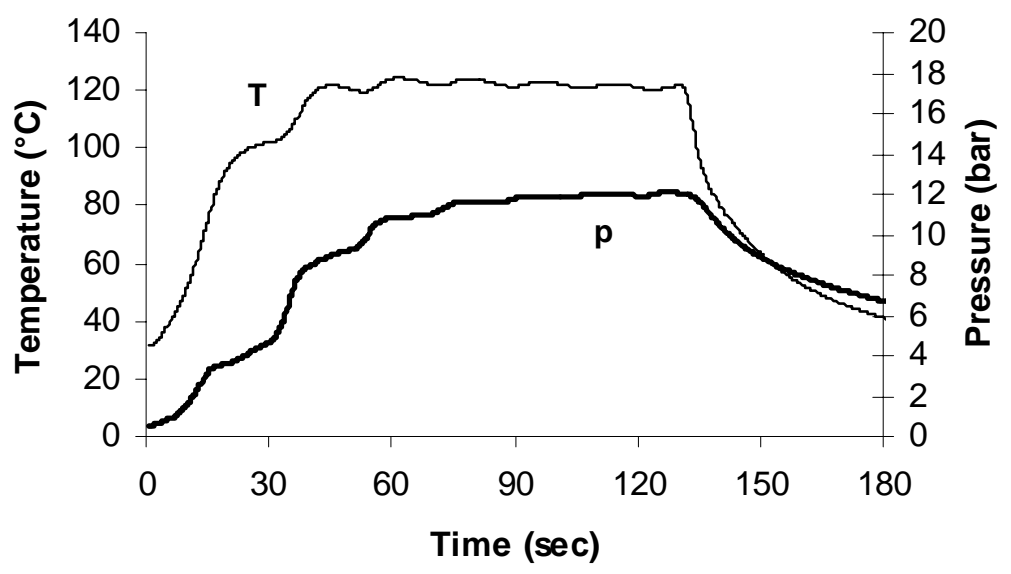

Figure 1. Temperature (T) and pressure (p) profiles for the reduction of DHPM $\mathbf{7} \rightarrow \mathbf{8}$ under sealed vessel/microwave irradiation conditions. ${ }^{\text {a }}$

${ }^{a}$ Microwave flash heating (300 W, 0-40 sec), temperature control using the feedback from IR thermography (constant $120^{\circ} \mathrm{C}, 40-130 \mathrm{sec}$ ), and active cooling (130-240 sec, last part not shown). The pressure remaining in the vial after the cooling period $\left(37^{\circ} \mathrm{C}\right)$ was $\mathrm{ca} .6 \mathrm{bar}$.

Having optimized conditions for the synthesis and reduction of the meta-nitrophenyl DHPM at hand, we subsequently carried out the analogous set of transformations with the orthosubstituted analog (Scheme 4). The corresponding DHPMs 9 and 10 were obtained in 54\% and $75 \%$ isolated yield, respectively. We next tried to obtain the desired intramolecular Michael addition by treating the amino compound $\mathbf{1 0}$ with the catalyst $p$-toluenesulfonic acid ${ }^{16 a}$ at roomor elevated temperature. In all cases a clean conversion to a new, less polar product was observed by TLC. The same compound also formed without catalysis (albeit very slowly) from $\mathbf{1 0}$ at room temperature in solvents such as ethanol. Disappointingly, however, spectroscopic analysis of the isolated product immediately ruled out the presence of the anticipated bridged pyrimidine 
derivative 11. From its mass- and simple ${ }^{1} \mathrm{H}-\mathrm{NMR}$ - spectrum, combined with its melting point, the obtained compound was readily identified as ethyl 2-methyl-3-quinolinecarboxylate (13). ${ }^{33}$ The optimized microwave-heated conditions used 5 min heating in EtOH, using $p$-TsOH as catalyst, to provide the quinoline $\mathbf{1 3}$ in near quantitative yield. The presumed reaction mechanism for this transformation is depicted in Scheme 4. Intramolecular Michael addition of the amino group on the aromatic ring onto the C-6- dihydropyrimidone carbon initially provides the anticipated triaza-polycycle 11. Apparently the cyclic aminal moiety in $\mathbf{1 1}$ can now fragment back to the dihydropyrimidone $\mathbf{1 0}$, or can undergo an alternative retro-Michael reaction to the dihydroquinoline 12, involving cleavage of the $\mathrm{C}-9-\mathrm{N}-10$ bond. The driving force for this latter cleavage pathway probably lies in the subsequent elimination of urea from 12 to furnish the thermodynamically very stable quinoline 13. A related rearrangement has been reported for the acid-catalyzed fragmentation of an ortho-aminophenyl-dihydropyridine-3,5-dicarboxylate (Hantzsch dihydropyridine) derivative. ${ }^{34}$ In this case, however, the analogous polycycle could be isolated under neutral or basic conditions, but disintegrated rapidly under acid catalysis. ${ }^{34}$

In conclusion we have demonstrated that the pharmacologically interesting triazapolycycles $\mathbf{6}$ are unstable scaffolds that disintegrate rapidly in a tandem Michael addition/elimination sequence. A novel microwave-promoted reduction of aromatic nitro groups by catalytic-transfer hydrogenation has also been presented.
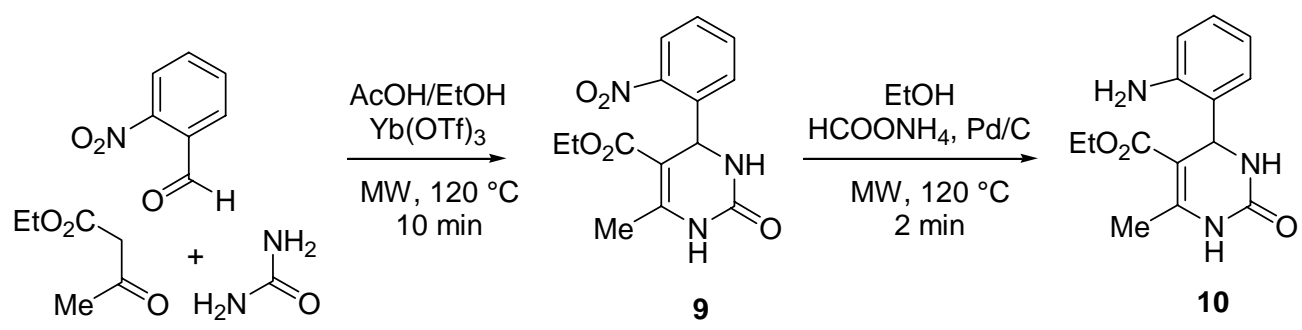

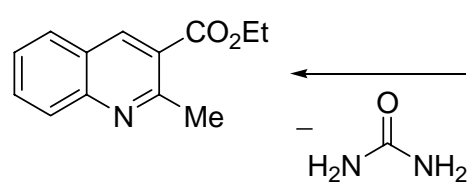

13

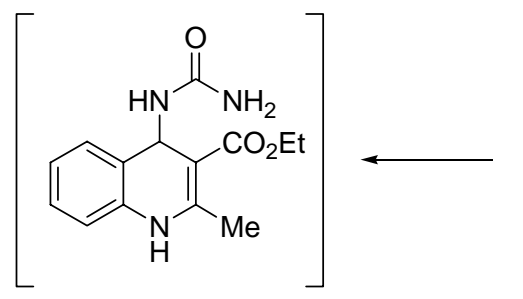

12
EtOH, p-TsOH
$\mathrm{MW}, 120^{\circ} \mathrm{C}, 5 \mathrm{~min}$

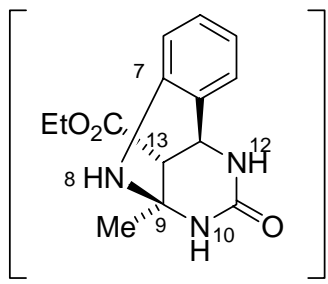

11

Scheme 4. Proposed mechanism for the rearrangement $\mathbf{1 0} \rightarrow \mathbf{1 3 .}$ 


\section{Experimental Section}

General Procedures. Melting points were determined on a Gallenkamp melting point apparatus Mod. MFB-595. ${ }^{1} \mathrm{H}$ - NMR spectra were recorded on Bruker AMX360 or AMX500 instruments in $\mathrm{CDCl}_{3}$ or d-6-DMSO, operating at 360 or $500 \mathrm{MHz}$, respectively. IR spectra were recorded on a Perkin-Elmer 298 spectrophotometer. Mass spectra were taken on a Hewlett-Packard LC/MSD 1100.

Series instrument in the atmospheric-pressure chemical-ionization (positive APCI) mode. Microanalyses were performed on a Carlo Erba 1106 elemental analyzer. Reactions were monitored by thin layer chromatography on $0.2 \mathrm{~mm}$ silica gel F-252 (Merck) plates. Ethyl acetoacetate, 2- and 3-nitrobenzaldehyde, ammonium formate, and urea were obtained from Aldrich Chemical Co. and used without further purification.

Microwave irradiation experiments. All microwave irradiation experiments were carried out using the Smith Synthesizer from PersonalChemistry AB (Uppsala) ${ }^{35}$ in the standard configuration. A detailed description of this single-mode microwave reactor with integrated robotics was published recently. ${ }^{6}$

Ethyl 6-methyl-4-(3-nitrophenyl)-2-oxo-1,2,3,4-tetrahydropyrimidine-5-carboxylate (7). A mixture of $4 \mathrm{mmol}$ (520 mg) ethyl acetoacetate, $4 \mathrm{mmol}$ (604 mg) 3-nitrobenzaldehyde, $4 \mathrm{mmol}$ (240 mg) urea and $0.4 \mathrm{mmol}(250 \mathrm{mg}) \mathrm{Yb}(\mathrm{OTf})_{3}$ was placed in a $5 \mathrm{~mL}$ Smith Process Vial ${ }^{\mathrm{TM}}$, equipped with a magnetic stirring bar. After $2 \mathrm{~mL}$ of a 3:1 AcOH/EtOH mixture was added, the vial was sealed with a Teflon septum and an alumina crimp top. The vessel was inserted into the

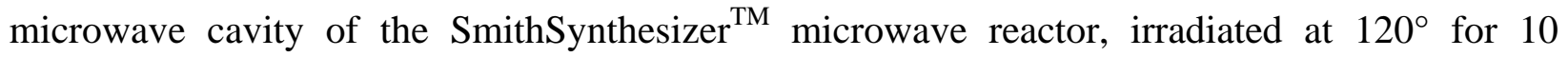
minutes and subsequently cooled by rapid gas-jet cooling. The vessel was removed from the cavity and allowed to stand in the refrigerator overnight. The formed precipitate was filtered by suction, washed with ice-cold EtOH and dried, to yield $964 \mathrm{mg}$ (79\%) of pyrimidine 7 (>95\% purity by ${ }^{1} \mathrm{H} \mathrm{NMR}$ ), mp $228{ }^{\circ} \mathrm{C}$ (acetic acid) (lit. ${ }^{19} \mathrm{mp} 226-227.5{ }^{\circ} \mathrm{C}$ ); IR (KBr): $\widetilde{v}\left[\mathrm{~cm}^{-1}\right] 3300$, 3120, 1710, 1690, 1630; ${ }^{1} \mathrm{H}$ NMR (DMSO- $d_{6}$ ): $\delta 1.11$ (t, $J=7.5 \mathrm{~Hz}, 3 \mathrm{H}$ ), 2.29 (s, 3H), 4.02 (q, $J$ = $7.5 \mathrm{~Hz}, 2 \mathrm{H}), 5.31$ (d, $J=3.0 \mathrm{~Hz}, 1 \mathrm{H}), 7.65-7.75$ (m, 2H), 7.95 (br s, 1H), 8.09-8.20 (m, 2H), 9.34 (br s, $1 \mathrm{H}$ ).

Ethyl 6-methyl-4-(2-nitrophenyl)-2-oxo-1,2,3,4-tetrahydropyrimidine-5-carboxylate (9). This compound was prepared in an manner analogous to the 3-nitro analog described above, employing 2-nitrobenzaldehyde, to yield $659 \mathrm{mg}$ (54\%) of the pyrimidine $9,{ }^{6} \mathrm{mp} 220{ }^{\circ} \mathrm{C}$ (acetic acid/methanol) (lit. ${ }^{36}$ 218-220 ${ }^{\circ} \mathrm{C}$ ); IR (KBr): $\tilde{v}\left[\mathrm{~cm}^{-1}\right]$ 3240, 3100, 1710, 1650; ${ }^{1} \mathrm{H}$ NMR (DMSO-d $)_{6}$ ): 0.94 (t, $\left.J=7.5 \mathrm{~Hz}, 3 \mathrm{H}\right), 2.30$ (s, 1H), 3.88 (q, $\left.J=7.5 \mathrm{~Hz}, 2 \mathrm{H}\right), 5.81$ (d, $J=3.0 \mathrm{~Hz}$, 1H), 7.49-7.98 (m, 5H), 9.39 (br s, 1H).

Ethyl 4-(3-aminophenyl)-6-methyl-2-oxo-1,2,3,4-tetrahydropyrimidine-5-carboxylate (8). A mixture of $1 \mathrm{mmol}$ (305 mg) of DHPM 7, $4 \mathrm{mmol}$ (250 mg) ammonium formate, and $3 \mathrm{~mL}$ of 
absolute ethanol was placed in a $5 \mathrm{~mL}$ Smith Process Vial ${ }^{\mathrm{TM}}$, equipped with a magnetic stirring bar. After $5 \mathrm{mg}$ palladium on charcoal (5\%) was added, the vial was sealed with a Teflon septum and an alumina crimp top. The vessel was inserted into the microwave cavity of the SmithSynthesizer ${ }^{\mathrm{TM}}$ microwave reactor, irradiated at $120^{\circ}$ for $130 \mathrm{~s}$ and subsequently cooled by rapid gas-jet cooling. The vessel was removed from the cavity and excess pressure (ca. 6 bar, see Figure 1) released by piercing the Teflon septum with a needle (CAUTION: toxic ammonia is released). The opened vessel was allowed to stand in the refrigerator overnight. The formed precipitate was filtered by suction and washed with ice-cold EtOH. In order to remove the catalyst the crude solid was dissolved in hot methanol, filtered through a plug of silica gel, and subsequently evaporated. The yield was $250 \mathrm{mg}$ (91\%) of pyrimidine 8 (>95\% purity by ${ }^{1} \mathrm{H}$ NMR), mp 210-212 ${ }^{\circ} \mathrm{C}$ (methanol) (lit. ${ }^{19} \mathrm{mp} 208.2-209.5^{\circ} \mathrm{C}$ ); IR (KBr): $\tilde{v}$ [ $\mathrm{cm}^{-1}$ ] 3390, 3220, 3080, 1710, 1685, 1650; ${ }^{1} \mathrm{H}$ NMR (DMSO- $d_{6}$ ): $\delta 1.11$ (t, $\left.J=7.5 \mathrm{~Hz}, 3 \mathrm{H}\right), 2.22$ (s, 3H), 3.97 (q, $J$ = $7.5 \mathrm{~Hz}, 2 \mathrm{H}), 4.98$ (d, $J=2.6 \mathrm{~Hz}, 1 \mathrm{H}), 5.05$, (br s, 2H), 6.37-6.43 (m, 3H), 6.89-6.94 (m, 1H), 7.61 (br s, 1H), 9.08 (br s, 1H).

Ethyl 4-(2-aminophenyl)-6-methyl-2-oxo-1,2,3,4-tetrahydropyrimidine-5-carboxylate (10). This compound was prepared in a manner analogous to the 3-amino analog described above, by reduction of DHPM 9, to yield $207 \mathrm{mg}$ (75\%) pyrimidine 10 as colorless crystals, mp 187-188 ${ }^{\circ} \mathrm{C}$ (methanol); IR (KBr): $\tilde{v}\left[\mathrm{~cm}^{-1}\right]$ 3390, 3220, 3080, 1710, 1685, 1650; ${ }^{1} \mathrm{H}$ NMR (DMSO-d $\mathrm{d}_{6}$ ): $\delta 1.06$ (t, $J=7.5 \mathrm{~Hz}, 3 \mathrm{H}), 2.29$ (s, 3H), 3.95 (q, $J=7.5 \mathrm{~Hz}, 2 \mathrm{H}), 4.96$ (s, 2H), 5.29 (d, $J=3.3 \mathrm{~Hz}$, $1 \mathrm{H}$ ), 6.46-6.98 (m, 4H), 7.34 (br s, $1 \mathrm{H}$ ), 9.13 (br s, $1 \mathrm{H}$ ). Anal. Calcd. for $\mathrm{C}_{14} \mathrm{H}_{17} \mathrm{~N}_{3} \mathrm{O}_{3}$ : C, 61.08; H, 6.22; N, 15.26. Found: C, 61.22; H, 6.01; N, 15.33\%.

Ethyl 2-methylquinoline-3-carboxylate (13). A mixture of $0.15 \mathrm{mmol}$ (41.3 mg) of DHPM 10, $3 \mathrm{~mL}$ of absolute ethanol, and a catalytic amount (ca. $4 \mathrm{mg}$ ) of p-toluenesulfonic acid was placed in a $5 \mathrm{~mL}$ Smith Process Vial ${ }^{\mathrm{TM}}$, equipped with a magnetic stirring bar. The vial was sealed with a Teflon septum and an alumina crimp top. The vessel was inserted into the microwave cavity of the SmithSynthesizer ${ }^{\mathrm{TM}}$ microwave reactor, irradiated at $120^{\circ}$ for 5 minutes and subsequently cooled by rapid gas-jet cooling. The vessel was removed from the cavity and the ethanol solution was evaporated. To remove the acidic catalyst and the urea formed, the crude product was dissolved in ethyl acetate and was rapidly filtered through a plug of silica gel to yield, after evaporation of the solvent, $30 \mathrm{mg}(93 \%)$ of the quinoline 13 , mp $69-70{ }^{\circ} \mathrm{C}$ (lit. ${ }^{33} \mathrm{mp} 72-$ $\left.72.5^{\circ} \mathrm{C}\right)$; IR (KBr): $\tilde{v}\left[\mathrm{~cm}^{-1}\right]$ 3050, 2985, 2920, 1720, 1620; ${ }^{1} \mathrm{H}$ NMR (DMSO- $\left.d_{6}\right): \delta 1.37(\mathrm{t}, J=$ $7.5 \mathrm{~Hz}, 3 \mathrm{H}$ ), 2.85 (s, 3H); 4.37 (q, $J=7.5 \mathrm{~Hz}, 2 \mathrm{H}$ ), 7.59-8.10 (m, 4H), 8.83 (s, 1H); MS (pos. APCI): $m / z 216(\mathrm{M}+1)$. Anal. Calcd. for $\mathrm{C}_{13} \mathrm{H}_{13} \mathrm{NO}_{2}$ : C, 72.54; H, 6.09; N, 6.51. Found: C, 72.82; H, 5.90; N, 6.55\%. 


\section{Acknowledgments}

We thank PersonalChemistry AB (Uppsala, Sweden) for use of the Smith Synthesizer microwave reactor.

\section{References and Notes}

1. Armstrong, R.W.; Combs, A. P.; Tempest, P. A.; Brown, S. D.; Keating, T. A. Acc. Chem. Res. 1996, 29, 123.

2. Dax, S. L.; McNally, J. J.; Youngman, M. A. Curr. Med. Chem. 1999, 6, 255.

3. Kappe, C. O. Acc. Chem. Res. 2000, 33, 879.

4. Kappe, C. O. Eur. J. Med. Chem. 2000, 35, 1043.

5. Lewandowski, K.; Murer, P.; Svec, F.; Fréchet, J. M. J. J. Comb. Chem. 1999, 1, 105.

6. Stadler, A.; Kappe, C. O. J. Comb. Chem. 2001, 3, 624.

7. Dondoni, A.; Massi, A. Tetrahedron Lett. 2001, 42, 7975.

8. Studer, A.; Jeger, P.; Wipf, P.; Curran, D. P. J. Org. Chem. 1997, 62, 2917.

9. Robinett, L. D.; Yager, K. M.; Phelan, J. C. $211^{\text {th }}$ National Meeting of the American Chemical Society, New Orleans, 1996; American Chemical Society: Washington, DC, 1996; ORGN 122.

10. Wipf, P.; Cunningham, A. Tetrahedron Lett. 1995, 36, 7819.

11. Kappe, C. O. Bioorg. Med. Chem. Lett. 2000, 10, 49.

12. Valverde, M. G.; Dallinger, D.; Kappe, C. O. Synlett 2001, 741.

13. For a recently described modified Biginelli-type condensation leading to spiroheterocycles, see the following. Byk, G.; Gottlieb, H. E.; Herscovici, J.; Mirkin, F. J. Comb. Chem. 2000, 2, 732.

14. Schreiber, S. L. Science 2000, 287, 1964.

15. Hartwig, J. F. Acc. Chem. Res. 1998, 31, 852.

16. Baldwin, J. J.; Claremon, D. A.; McClure, D. E. (Merck and Co., Inc., USA) U.S. Patent 1986, 4,608,494. (b) Svetlik, J.; Hanus, V.; Bella, J. J. Chem. Res., Synop. 1991, 4. (c) Rehani, R.; Shah, A. C.; Arya, V. P. Ind. J. Chem. 1994, 33B, 775. (d) Kettmann, V.; Svetlik, J. Acta Cryst. 1996, 52C, 1496. (e) Kettmann, V.; Svetlik, J. Acta Cryst. 1997, 53C, 1493.

17. Kappe, C. O.; Fabian, W. M. F.; Semones, M. A. Tetrahedron 1997, 53, 2803.

18. Kappe, C. O. Tetrahedron 1993, 49, 6937.

19. Folkers, K.; Harwood, H. J.; Johnson, T. B. J. Am. Chem. Soc. 1932, 54, 3751.

20. Bruce, M.; Pointdexter, G. S.; Johnson, G. (Bristol-Myers Squibb Co., USA) PCT 1998 WO 98/33791. 
21. For general reviews, see: (a) Lidström, P.; Tierney, J.; Wathey, B.; Westman, J. Tetrahedron 2001, 57, 9222. (b) Caddick, S. Tetrahedron 1995, 51, 10403. (c) Bose, A. K.; Banik, B. K.; Lavlinskaia, N.; Jayaraman, M.; Manhas, M. S. Chemtech 1997, 27, 18. (d) Strauss, C. R.; Trainor, R. W. Aust. J. Chem. 1995, 48, 1665.

22. Review: de la Hoz, A.; Díaz-Ortis, A.; Moreno, A.; Langa, F. Eur. J. Org. Chem. 2000, 3659.

23. Review: Varma, R. S. J. Heterocycl. Chem. 1999, 36, 1565.

24. Review: Elander, N.; Jones, J. R.; Lu, S.-Y.; Stone-Elander, S. Chem. Soc. Rev. 2000, 239.

25. For example, see: Kaiser, N.-F. K.; Bremberg, U.; Larhed, M.; Moberg, C.; Hallberg, A. Angew. Chem. 2000, 112, 3742.

26. Reviews: (a) Varma, R. S. Green Chem. 1999, 43. (b) Loupy, A.; Petit, A.; Hamelin, J.; Texier-Boullet, F.; Jacquault, P.; Mathé, D. Synthesis 1998, 1213.

27. Deshayes, S.; Liagre, M.; Loupy, A.; Luche, J.-L.; Petit, A. Tetrahedron 1999, 55, 10851.

28. Larhed, M.; Hallberg, A. Drug Discovery Today 2001, 6, 406.

29. Krstenansky, J. L.; Cotterill, I. Curr. Opin. Drug Discovery Dev. 2000, 4, 454.

30. Banik, B. K.; Barakat, K. J.; Wagle, D. R.; Manhar, M. S.; Bose, A. K. J. Org. Chem. 1999, 64, 5746.

31. Desai, B.; Danks, T. N. Tetrahedron Lett. 2001, 42, 5963.

32. For alternative methods to reduce the C5=C6 double bond in DHPM, see ref. 18.

33. Sicker, D.; Rabe, A.; Zakrzewski, A.; Mann, G.; J. Prakt. Chem. 1987, 329, 1063. (b) Sicker, D.; Mann, G.; Z. Chem. 1985, 25, 365.

34. Kim, D. H. J. Heterocycl. Chem. 1986, 23, 1471.

35. PersonalChemistry AB, Kungsgatan 76, SE-753 18 Uppsala, Sweden; Phone: (Internat.) +46-18 4899000; Fax: (Internat.) 46-18-4899100; http://www.personalchemistry.com.

36. Kappe, C. O.; Wagner, U. G. Heterocycles 1989, 29, 761. 